\title{
Improved Synthesis of Polyether-Aramid Multi-Block Copolymers by Direct Polycondensation
}

\author{
Yoshio ImaI, Mikio KaJiYama, Shin-ichi Ogata, \\ and Masa-aki KAKIMOTO \\ Department of Textile and Polymeric Materials, \\ Tokyo Institute of Technology, \\ Meguro-ku, Tokyo 152, Japan
}

(Received April 25, 1985)

\begin{abstract}
Polyether-aramid multi-block copolymers having structural regularity were synthesized by a one-pot two-step method of direct polycondensation using triphenyl phosphite and pyridine as condensing agents. Amine-terminated telechelic aramid oligomers were prepared by the reaction of bis(4-aminophenyl) ether and isophthalic acid, and subsequently condensed with $\alpha, \omega$ poly(oxyethylene)dicarboxylic acid giving the multi-block copolymers with inherent viscosities of $0.5-0.7 \mathrm{dl} \mathrm{g}^{-1}$. No appreciable differences in thermal and tensile properties were observed between the multi-block copolymers thus prepared and those synthesized by the previously reported two-pot method. In contrast, the properties of these block copolymers differed significantly from those of a randomly coupled block copolymers prepared by the one-step procedure.

KEY WORDS Polyether-Aramid Multi-Block Copolymers / Direct

Polycondensation / Solubility / Thermal Behavior / Tensile Properties /
\end{abstract}

In our previous paper $^{1}$ dealing with the synthesis of multi-block copolymers based on poly(oxyethylene)s and aromatic polyamides (aramids), it was reported that polyetheraramid multi-block copolymers can be obtained by the direct polycondensation of amine-terminated telechelic aramid oligomers (aramid diamines) with $\alpha, \omega$-poly(oxyethylene)dicarboxylic acids (POE-diacids) using triphenyl phosphite and pyridine as condensing agents. This synthetic procedure, referred to as a two-pot method, is advantageous for the synthesis of the multi-block copolymers having high structural regularity but is somewhat troublesome because of the isolation of aramid diamines in the first stage. The present work was undertaken to observe whether an improved one-pot twostep method, which consists of in situ preparation of aramid diamines and subsequent poly- condensation with POE-diacids in one-pot, could be worked out for synthesizing the multi-block copolymers with well-defined structures. The simplest one-step method, where parent aromatic diamine and dicarboxylic acid for aramid diamine, and POEdiacids are reacted together, was also investigated for comparison.

\section{EXPERIMENTAL}

\section{Materials}

POE-diacid (1) having a number average molecular weight of 3400 , determined by titration, was supplied by Kawaken Fine Chemicals Corp. Bis(4-aminophenyl)ether (ODA) and isophthalic acid (IPA) were purified by recrystallization from tetrahydrofuran and aqueous ethanol, respectively. Triphenyl phosphite, pyridine, $N$-methyl-2- 
pyrrolidone (NMP), and $N, N$-dimethylacetamide (DMAc) were purified by distillation. Inorganic salts such as lithium chloride and calcium chloride were used as received.

Synthesis of Multi-Block Copolymers 3 (I/II) by One-Pot Two-Step Method

Block copolymer $\mathbf{3 b}(I / I I)$. A mixture of $1.20 \mathrm{~g}(6 \mathrm{mmol})$ of ODA, $0.83 \mathrm{~g}(5 \mathrm{mmol})$ of IPA, $4 \mathrm{ml}$ of triphenyl phosphite, $0.5 \mathrm{~g}$ of lithium chloride, and $0.25 \mathrm{~g}$ of calcium chloride in $5 \mathrm{ml}$ of pyridine and $10 \mathrm{ml}$ of NMP were heated with stirring at $100^{\circ} \mathrm{C}$ for $3 \mathrm{~h}$ under nitrogen. To the reaction solution, $3.40 \mathrm{~g}$ ( $1 \mathrm{mmol}$ ) of solid 1 and a solution of $0.5 \mathrm{~g}$ of lithium chloride and $0.25 \mathrm{~g}$ of calcium chloride in $5 \mathrm{ml}$ of pyridine and $10 \mathrm{ml}$ of NMP were added, and then the mixture was stirred for another $3 \mathrm{~h}$ at the same temperature. The resultant polymer was isolated by pouring the reaction mixture into $1000 \mathrm{ml}$ of methanol. The product was purified by reprecipitation from DMAc-methanol, followed by thorough washings with hot methanol and drying at $30^{\circ} \mathrm{C}$ in vacuo. The yield was $4.43 \mathrm{~g}(82 \%)$. Inherent viscosity of the polymer in DMAc was $0.69 \mathrm{dlg}^{-1}$, measured at a concentration of $0.5 \mathrm{gdl}^{-1}$ at $30^{\circ} \mathrm{C}$. The IR spectrum (film) exhibited absorptions at $3300 \mathrm{~cm}^{-1}(\mathrm{~N}-\mathrm{H})$, $1660 \mathrm{~cm}^{-1}(\mathrm{C}=\mathrm{O})$, and 1225 and $1100 \mathrm{~cm}^{-1}$ (C-O-C).

Similarly, other block copolymers of I/II series were prepared by analogous procedure. calcium chloride in $10 \mathrm{ml}$ of pyridine and $20 \mathrm{ml}$ of NMP was heated with stirring at $100^{\circ} \mathrm{C}$ for $3 \mathrm{~h}$ under nitrogen. The polymer was isolated and purified as described above. The product weighed $4.70 \mathrm{~g}(87 \%)$ and had an inherent viscosity of $0.75 \mathrm{dlg}^{-1}$ in DMAc. The IR spectrum (film) showed absorptions at $3300 \mathrm{~cm}^{-1}$ $(\mathrm{N}-\mathrm{H}), 1650 \mathrm{~cm}^{-1}(\mathrm{C}=\mathrm{O})$, and 1225 and $1100 \mathrm{~cm}^{-1}(\mathrm{C}-\mathrm{O}-\mathrm{C})$.

An analogous one-step procedure was applied in the preparation of other block copolymers of I series.

\section{Measurements}

IR spectra were recorded on a Hitachi EPG3 spectrophotometer. Differential scanning calorimetry (DSC) was performed with Du Pont 910-DSC/990-TA thermal analyzers. Transmission electron microscopy was observed with a Hitachi HLJ-12 electron microscope. Small-angle X-ray diffraction patterns were obtained for film specimens at room temperature on a Rigakudenki RU-200 X-ray diffraction apparatus with nickel-filtered $\mathrm{Cu}-K \alpha$ radiation $(50 \mathrm{kV}, 200 \mathrm{~mA})$. Tensile properties were determined from stress-strain curves obtained with a Toyo Baldwin Tensilon UTM-III at an elongation rate of $20 \% \mathrm{~min}^{-1}$. Measurements were performed at room temperature with film specimens $(1.0 \mathrm{~cm}$ wide, $5.0 \mathrm{~cm}$ long, and about $0.1 \mathrm{~mm}$ thick) and the average of at least five individual determinations was taken.

\section{RESULTS AND DISCUSSION}

\section{One-Step Method}

Block Copolymer $3 \mathbf{b}(I)$. A mixture of $1.20 \mathrm{~g}$ $(6 \mathrm{mmol})$ of ODA, $0.83 \mathrm{~g}(5 \mathrm{mmol})$ of IPA, $3.40 \mathrm{~g}$ ( $1 \mathrm{mmol})$ of $1,4 \mathrm{ml}$ of triphenyl phosphite, $1.0 \mathrm{~g}$ of lithium chloride, and $0.5 \mathrm{~g}$ of

$$
\begin{aligned}
& (\mathrm{y}+1) \mathrm{H}_{2} \mathrm{N-Ar- \textrm {NH } _ { 2 }}+\mathrm{y} \prod_{0}^{\mathrm{HOC}}-\mathrm{Ar}^{\prime}-\prod_{\mathrm{O}}^{\mathrm{COH}}
\end{aligned}
$$

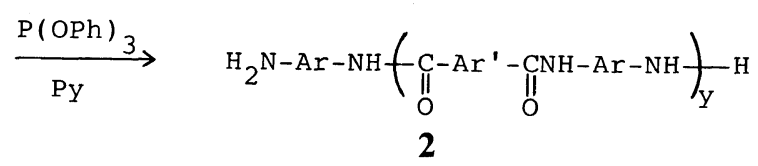

\section{Copolymers}

Synthetic sheme for polyether-aramid multiblock copolymers is shown in eq 1 . 


$$
\begin{aligned}
& \frac{\stackrel{\mathrm{O}}{\mathrm{HOCCH}} \mathrm{O}_{2}\left(\mathrm{CH}_{2} \mathrm{CH}_{2} \mathrm{O}\right)_{\mathrm{x}-1} \mathrm{CH}_{2} \stackrel{\mathrm{O}}{\mathrm{COH}} 1}{\mathrm{P}(\mathrm{OPh})_{3}+\mathrm{Py}} \\
& {\left[-\underset{\mathrm{O}}{\mathrm{C}}\left(-\mathrm{CH}_{2} \mathrm{OCH}_{2}\right)_{\mathrm{x}} \prod_{\mathrm{O}}^{\mathrm{CNH}-\mathrm{Ar}-\mathrm{NH}}\left(\prod_{\mathrm{O}}^{\mathrm{C}-\mathrm{Ar}}-\prod_{0}^{\mathrm{CNH}-\mathrm{Ar}-\mathrm{NH}}\right)_{\mathrm{y}}\right]_{\mathrm{n}}} \\
& 3 \\
& \text { Ar : } O-O A r^{\prime}: \\
& \widehat{O}
\end{aligned}
$$

The synthesis of multi-block copolymers 3(I/II) was perfomed by the one-pot two-step method. The reaction of IPA with calculated excess of ODA in the presence of triphenyl phosphite and pyridine in NMP afforded a solution of aramid diamine 2 , which in turn was subjected to polycondensation with POEdiacid 1 giving multi-block copolymers 3(I/II). The calculated amounts of IPA and ODA were used to form aramid diamines having a desired number average molecular weight $\left(M_{n}\right)$, and exactly the equal molar amount of POEdiacid 1 was used to the amount of aramid diamine 2 prepared in situ. From combinations of POE-diacid $\mathbf{1}$ and four aramid diamines 2a-2d with $M_{n}$ ranging from 1200 to 5500 , multi-block copolymers 3a(I/II)3d(I/II) were obtained in high molecular weights as suggested by their high inherent viscosities $\left(0.5-0.7 \mathrm{dlg}^{-1}\right)$.

The simplest one-step method was applied to the preparation of block copolymers $3(\mathrm{I})$. Three reaction components, ODA and IPA for aramid diamine, and POE-diacid, were reacted together in NMP using triphenyl phosphite and pyridine as the condensing agents. Block copolymers 3(I) having inherent viscosities of $0.6-0.9 \mathrm{dlg}^{-1}$ were obtained in almost quantitative yields.

The results of the synthesis of block copolymers of 3(I/II) and 3(I) series, as well as previously reported block copolymers 3 (II) by

\begin{tabular}{|c|c|c|c|}
\hline \multirow{3}{*}{$\begin{array}{l}\text { Method of } \\
\text { preparation }^{\mathrm{a}}\end{array}$} & \multirow{3}{*}{$\begin{array}{c}M_{n} \text { of aramid } \\
\text { oligomer }\end{array}$} & \multicolumn{2}{|c|}{ Block copolymer } \\
\hline & & \multirow{2}{*}{ Code } & $\eta_{\mathrm{inh}}^{\mathrm{b}}$ \\
\hline & & & $\mathrm{dl} \mathrm{g}^{-1}$ \\
\hline II & 2000 & $3 b(I I)$ & 0.64 \\
\hline II & 3300 & $3 c(I I)$ & 0.65 \\
\hline II & 5400 & $3 d(I I)$ & 0.52 \\
\hline $\mathrm{I} / \mathrm{II}$ & 1200 & $3 \mathbf{a}(\mathrm{I} / \mathrm{II})$ & 0.50 \\
\hline $\mathrm{I} / \mathrm{II}$ & 1900 & $3 \mathrm{~b}(\mathrm{I} / \mathrm{II})$ & 0.69 \\
\hline $\mathrm{I} / \mathrm{II}$ & 3200 & $3 \mathbf{c}(\mathrm{I} / \mathrm{II})$ & 0.51 \\
\hline $\mathrm{I} / \mathrm{II}$ & 5500 & $3 d(I / I I)$ & 0.57 \\
\hline $\mathrm{I}$ & 1200 & $\mathbf{3 a}(\mathrm{I})$ & 0.67 \\
\hline I & 1900 & $3 b(I)$ & 0.75 \\
\hline I & 3200 & $3 c(I)$ & 0.71 \\
\hline I & 5500 & 3d(I) & 0.93 \\
\hline
\end{tabular}
the two-pot method, ${ }^{1}$ are summarized in Table I. The inherent viscosity values of $3(\mathrm{I} / \mathrm{II})$ were
Table I. Synthesis of polyetheraramid multi-block copolymers

a II, two-pot method; I/II, one-pot two-step method; and I, one-step method.

\begin{tabular}{|c|c|c|c|c|c|c|}
\hline \multirow{2}{*}{$\begin{array}{c}\text { Block } \\
\text { copolymer }\end{array}$} & \multicolumn{3}{|c|}{ Calcd $/ \%$} & \multicolumn{3}{|c|}{ Found $/ \%$} \\
\hline & $\mathrm{C}$ & $\mathbf{H}$ & $\mathbf{N}$ & $\mathrm{C}$ & $\mathrm{H}$ & $\mathrm{N}$ \\
\hline $3 \mathbf{c}(\mathrm{II})$ & 63.40 & 6.65 & 4.35 & 61.76 & 6.57 & 3.88 \\
\hline $3 \mathbf{c}(\mathrm{I} / \mathrm{II})$ & - & - & - & 61.75 & 6.40 & 4.43 \\
\hline $3 \mathbf{c}(\mathrm{I})$ & - & - & - & 62.57 & 6.45 & 4.41 \\
\hline 3d(II) & 65.63 & 6.08 & 5.33 & 64.17 & 5.85 & 4.80 \\
\hline $\mathbf{3 d}(\mathrm{I} / \mathrm{II})$ & - & - & - & 65.48 & 5.87 & 5.47 \\
\hline $3 d(I)$ & - & - & - & 66.33 & 5.87 & 5.32 \\
\hline
\end{tabular}

b Measured at a concentration of $0.5 \mathrm{~g} \mathrm{dl}^{-1}$ in DMAc at $30^{\circ} \mathrm{C}$.

Table II. Elemental analysis of polyether-aramid multi-block copolymers 
almost the same as those of 3(II), whereas the values of 3(I) were comparatively higher than those of 3(I/II) and 3(II).

The structure of the resulting polymers was confirmed by IR spectroscopy and elemental analysis (Table II). The IR spectra of all the block copolymers 3(I/II) and 3(I) were almost identical with those of multi-block copolymers 3(II). ${ }^{1}$ In the IR spectra of both $3(\mathrm{I} / \mathrm{II})$ and 3(I), characteristic amide absorptions at $3300 \mathrm{~cm}^{-1}(\mathrm{~N}-\mathrm{H})$ and $1660 \mathrm{~cm}^{-1}(\mathrm{C}=\mathrm{O})$, and ether absorptions at 1225 and $1100 \mathrm{~cm}^{-1}$ appeared, while a strong carbonyl absorption at $1740 \mathrm{~cm}^{-1}$ due to the carboxylic function of the starting POE-diacid disappeared.

\section{Properties of Polyether-Aramid Multi-block Copolymers}

Both block copolymers of 3(I/II) and 3(I) are readily soluble in DMAc, but insoluble in other organic solvents including NMP, pyridine, $m$-cresol, and formic acid. The difference in solubility between $3(\mathrm{I} / \mathrm{II})$ and $3(\mathrm{I})$ was not observed clearly. Furthermore, the solubility behavior of these block copolymers was the same as that of multi-block copolymers 3(II). ${ }^{1}$

Transparent, ductile, and elastomeric films could be cast from the DMAc solutions of all the block copolymers. From small-angle X-ray diffraction studies of the films, a diffraction peak was observed at a diffraction angle of $10.6,12.0$, and $11.2 \mathrm{~min}$, for polymer films $3 \mathbf{c}(\mathrm{II}), \mathbf{3 c}(\mathrm{I} / \mathrm{II})$, and $\mathbf{3 c}(\mathrm{I})$, respectively. The average interdomain distance for $3 c(I I)$, $3 \mathbf{c}(\mathrm{I} / \mathrm{II})$, and $3 \mathbf{c}(\mathrm{I})$ was calculated to be 25,22 , and $24 \mathrm{~nm}$, respectively, from known Bragg's equation. The above results suggest that all of these transparent films have micro-phase separated structures.

In order to obtain more information about the microstructure of films of block copolymers, the films were examined by transmission electron microscopy using osmium tetraoxide or ruthenium tetraoxide as a staining agent. $^{2}$ However, attempts to prepare the
Table III. Glass transition temperatures ( $T_{\mathrm{g}}$ ) of poly(oxyethylene) segment in polymer-aramid multi-block copolymers

\begin{tabular}{|c|c|c|c|c|}
\hline \multirow{2}{*}{$\begin{array}{c}\text { Block } \\
\text { copolymer }\end{array}$} & \multirow{2}{*}{$\begin{array}{c}\begin{array}{c}\text { POE } \\
\text { content }\end{array} \\
\mathrm{wt} \%\end{array}$} & \multicolumn{3}{|c|}{$T_{\mathrm{g}}^{\mathrm{a} /{ }^{\circ} \mathrm{C}}$} \\
\hline & & $\begin{array}{c}\text { (II) } \\
\text { series }\end{array}$ & $\begin{array}{l}(\mathrm{I} / \mathrm{II}) \\
\text { series }\end{array}$ & $\begin{array}{c}\text { (I) } \\
\text { series }\end{array}$ \\
\hline $3 \mathbf{a}$ & 74 & - & -39 & -27 \\
\hline 3b & 63 & -36 & -33 & -28 \\
\hline $3 c$ & 51 & -34 & -36 & -28 \\
\hline 3d & 39 & -33 & -31 & -30 \\
\hline $\mathrm{POE}^{\mathrm{b}}$ & 100 & -38 & -38 & -38 \\
\hline
\end{tabular}

a Determined by DSC at a heating rate of $20^{\circ} \mathrm{C} \mathrm{min}^{-1}$ in air.

b Poly(oxyethylene) homopolymer $\left(M_{n}=20000\right)$.

micrographs having high image contrast were unsuccessful.

Two-phase polymers that segregate into distinct large domains usually exhibit two glass transition temperatures $\left(T_{\mathrm{g}} \mathrm{s}\right)$ identical with those of the component polymers. When the domains are very small, the $T_{\mathrm{g}} \mathrm{s}$ of the indivisual components shift; elevation of the temperature of the low $T_{\mathrm{g}}$ and depression of the high $T_{\mathrm{g}}$. This inward-shift phenomenon has been reported for many block copolymers. ${ }^{3}$ The $T_{\mathrm{g}} \mathrm{s}$ of multi-block copolymers 3(II), 3(I/II), and 3(I) were evaluated by means of DSC. The high $T_{\mathrm{g}} \mathrm{s}$ based on the aramid phase in the block copolymers could not be detected in the $250^{\circ} \mathrm{C}$ region because of the appearance of a strong exothermic peak due to decomposition of the poly(oxyethylene) (POE) phase, while the low $T_{\mathrm{g}} \mathrm{s}$ based on the POE phase were detected clearly in the $-30^{\circ} \mathrm{C}$ region. As can be seen from Table III, the $T_{\mathrm{g}} \mathrm{s}$ of the POE phase remained almost unchanged over all the POE content, or tended to increase to some extent with decreasing POE content in the multi-block copolymers of the indivisual series.

No appreciable difference in the extent of $T_{\mathrm{g}}$ elevation was observed between block copolymers 3(II) and 3(I/II), whereas the change of the $T_{\mathrm{g}}$ of block copolymers $3(\mathrm{I})$ was rather 


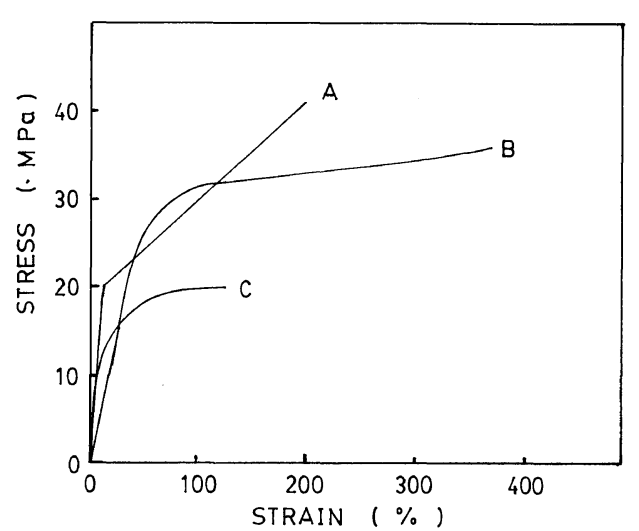

Figure 1. Stress-strain curves of films of polyetheraramid multi-block copolymer 3d(II) (A), 3d(I/II) (B), and $3 \mathbf{d}(\mathrm{I})(\mathrm{C})$.

Table IV. Tensile properties of cast films of polyether-aramid multi-block copolymers

\begin{tabular}{|c|c|c|c|c|}
\hline \multirow{2}{*}{$\begin{array}{c}\text { Block } \\
\text { copolymer }\end{array}$} & $\begin{array}{c}\text { Tensile } \\
\text { strength }\end{array}$ & $\begin{array}{l}\text { Elongation } \\
\text { at break }\end{array}$ & $\begin{array}{l}\text { Tensile } \\
\text { modulus }\end{array}$ & $\begin{array}{l}\text { Elastic } \\
\text { recovery }\end{array}$ \\
\hline & $\mathrm{MPa}$ & $\%$ & $\mathrm{MPa}$ & $\%$ \\
\hline $3 a(I / I I)$ & 4.9 & 320 & 8 & 76 \\
\hline $3 a(I)$ & 2.8 & 280 & 8 & 53 \\
\hline $3 b(I I)$ & 6.9 & 370 & 6 & 100 \\
\hline $3 b(\mathrm{I} / \mathrm{II})$ & 7.0 & 860 & 6 & 88 \\
\hline $3 b(I)$ & 3.2 & 350 & 5 & 66 \\
\hline $3 c(I I)$ & 29 & 320 & 470 & 86 \\
\hline $3 c(I / I I)$ & 26 & 290 & 240 & 79 \\
\hline $3 c(I)$ & 11 & 280 & 440 & 81 \\
\hline $3 d(I I)$ & 42 & 200 & 500 & 58 \\
\hline $3 d(I / I I)$ & 36 & 360 & 300 & 53 \\
\hline $\mathbf{3 d}(\mathrm{I})$ & 20 & 140 & 700 & 49 \\
\hline Aramid $^{b}$ & 68 & 4 & 1700 & - \\
\hline
\end{tabular}

a Measured by $100 \%$ extension of film specimens and relaxation.

b Aramid homopolymer prepared by polycondensation of $4,4^{\prime}$-ODA and IPA. Inherent viscosity was $0.80 \mathrm{dl} \mathrm{g}^{-1}$ measured at a concentration of $0.5 \mathrm{~g} \mathrm{dl}^{-1}$ in DMAc at $30^{\circ} \mathrm{C}$.

large as compared with block copolymers 3(II) and 3(I/II). This fact may suggest that block copolymers 3(I/II) have high structural regularity, very similar to multi-block copolymers 3(II), ${ }^{1}$ while block copolymers 3(I) are randomly coupled block copolymers having some irregular structures.
Stress-strain curves of the films of block copolymers 3(II), 3(I/II), and 3(I) were obtained by a tensile tester. Typical curves are shown in Figure 1, and the tensile properties are summarized in Table IV. The films have ductile and elastomeric properties depending markedly on the content of aramid blocks which acts as pseudo-crosslinking sites. In general, tensile strength and modulus increased with increasing the aramid content, whereas elongation at break decreased. Similar structure-property relationships have been reported in polybutadiene-aramid multi-block copolymers. $^{4,5}$

The influence of the molecular structures of the block copolymers, mainly depending on the methods of polymer synthesis, was further observed on the tensile properties. Although the films of block copolymers 3(I/II) have somewhat lower tensile strength and higher elongation at break than those of multi-block copolymers 3(II) with well-defined structures, the difference in the tensile values is rather small between these two block copolymers. But both the tensile strength and elongation at break for the films of block copolymers 3(I) are less than those of block copolymers 3(I/II) and 3(II). This suggests that block copolymers 3(I) have some irregularly coupled structures, compared with block copolymers $3(\mathrm{I} / \mathrm{II})$ as well as multi-block copolymers 3 (II) having high structural regularity. It is, therefore, concluded that the synthesis of polyether-aramid multi-block copolymers, whose structures are very similar to those of multi-block copolymers 3(II) prepared by the troublesome twopot procedure, were greatly impoved through the simple one-pot two-step method.

Acknowledgment. We are indebted to $\mathrm{Mr}$. T. Katsuta of Japan Synthetic Rubber Co., Tokyo, for preparing the electron micrographs, to Dr. H. Ikeda of the same company for the thermal measurements, and to Professor K. Miyasaka for the X-ray diffraction studies and for the tensile property de- 


\section{Y. IMAI et al.}

terminations. We also thank Professor T. Inoue for helpful comments.

\section{REFERENCES}

1. Y. Imai, M. Kajiyama, S. Ogata, and M. Kakimoto, Polym. J., 16, 267 (1984).
2. M. Kita, H. Tanaka, and T. Shimada, Sen-i Gakkaishi, 40, T-411 (1984).

3. T. Inoue, S. Ogata, M. Kakimoto, and Y. Imai, Macromolecules, 17, 1417 (1984).

4. S. Ogata, M. Kakimoto, and Y. Imai, Macromolecules, 18, 851 (1985).

5. S. Ogata, H. Maeda, M. Kakimoto, and Y. Imai, Polym. J., 17, 935 (1985). 